\title{
Correction to: Thermofluidic compression effects to achieve combustion in a low-compression scramjet engine
}

\author{
A. F. Moura ${ }^{1} \cdot$ V. Wheatley ${ }^{1} \cdot$ I. Jahn ${ }^{1}$
}

Published online: 4 June 2019

○) Springer-Verlag GmbH Germany, part of Springer Nature 2019

\section{Correction to:}

Shock Waves (2018) 28:863-875

https://doi.org/10.1007/s00193-017-0782-0

In the original article publication, Equation no. 2 is incorrectly published. The correct equation is:

$Y_{\mathrm{H}_{2}}^{\mathrm{r}}= \begin{cases}Y_{\mathrm{H}_{2}} & Y_{\mathrm{H}_{2}} \leq Y_{\mathrm{H}_{2}}^{\text {stoic }} \\ \left(\frac{1-Y_{\mathrm{H}_{2}}}{1-Y_{\mathrm{H}_{2}}^{\text {stoic }}}\right) Y_{\mathrm{H}_{2}}^{\text {stoic }} & Y_{\mathrm{H}_{2}}>Y_{\mathrm{H}_{2}}^{\text {stoic }}\end{cases}$

Publisher's Note Springer Nature remains neutral with regard to jurisdictional claims in published maps and institutional affiliations.

The original article can be found online at https://doi.org/10.1007/ s00193-017-0782-0.

A. F. Moura afmoura@protonmail.com

1 The University of Queensland, Brisbane, QLD 4066, Australia 